\title{
Tryptophan depletion impairs memory consolidation but improves focussed attention in healthy young volunteers
}

Citation for published version (APA):

Schmitt, J. A. J., Jorissen, B. L., Sobczak, S., van Boxtel, M. P. J., Hogervorst, E., Deutz, N. E. P., \& Riedel, W. J. (2000). Tryptophan depletion impairs memory consolidation but improves focussed attention in healthy young volunteers. Journal of Psychopharmacology, 14(1), 21-29. https://doi.org/10.1177/026988110001400102

Document status and date:

Published: 01/01/2000

DOI:

10.1177/026988110001400102

Document Version:

Publisher's PDF, also known as Version of record

\section{Document license:}

Taverne

Please check the document version of this publication:

- A submitted manuscript is the version of the article upon submission and before peer-review. There can be important differences between the submitted version and the official published version of record.

People interested in the research are advised to contact the author for the final version of the publication, or visit the DOI to the publisher's website.

- The final author version and the galley proof are versions of the publication after peer review.

- The final published version features the final layout of the paper including the volume, issue and page numbers.

Link to publication

\footnotetext{
General rights rights.

- You may freely distribute the URL identifying the publication in the public portal. please follow below link for the End User Agreement:

www.umlib.nl/taverne-license

Take down policy

If you believe that this document breaches copyright please contact us at:

repository@maastrichtuniversity.nl

providing details and we will investigate your claim.
}

Copyright and moral rights for the publications made accessible in the public portal are retained by the authors and/or other copyright owners and it is a condition of accessing publications that users recognise and abide by the legal requirements associated with these

- Users may download and print one copy of any publication from the public portal for the purpose of private study or research.

- You may not further distribute the material or use it for any profit-making activity or commercial gain

If the publication is distributed under the terms of Article $25 \mathrm{fa}$ of the Dutch Copyright Act, indicated by the "Taverne" license above, 


\title{
Tryptophan depletion impairs memory consolidation but improves focussed attention in healthy young volunteers
}

\author{
Jeroen A. J. Schmitt1, Brenda L. Jorissen1, Sjacko Sobczak1, Martin P. J. van Boxtel1, \\ Eef Hogervorst1, Nicolaas E. P. Deutz² and Wim J. Riedel1
}

Departments of ${ }^{1}$ Psychiatry and Neuropsychology and ${ }^{2}$ Surgery, Brain and Behavior Institute, European Graduate School for Neurosciences, Maastricht University, The Netherlands

Animal and human studies have provided evidence for serotonergic modulation of cognitive processes. However, the exact nature of this relationship is not clear. We used the acute tryptophan depletion (ATD) method to investigate the effects of lowered serotonin synthesis on cognitive functions in 17 healthy young volunteers. The study was conducted according to a placebo-controlled, double-blind, crossover design. Cognitive performance and mood were assessed at baseline and 5 and $9 \mathrm{~h}$ after administration of ATD. A specific impairment of word recognition, without effects on short-term memory, occurred during ATD. No memory deficits were seen if ATD was induced after acquisition of new words. The Stroop Test and dichotic listening task demonstrated a modality independent improvement of focussed attention after ATD. Fluency was also improved after ATD. ATD did not alter speed of information processing, divided attention or planning functions. These results indicate that serotonin is essential in the process of long-term memory consolidation, primarily in the first $30 \mathrm{~min}$ after acquisition. Improvement of specific cognitive processes by lowered 5-HT function may be linked to the removal of inhibitory actions of 5-HT in the cortex.

Key words: amino acids; attention; cognition; memory; serotonin; tryptophan depletion

\section{Introduction}

Studies into the role of serotonin (5-hydroxytryptamine, 5-HT) in cognitive functioning have provided evidence for a serotonergic involvement in cognitive processes such as memory and attention. However, the exact nature of this relationship is not clear. Most studies in this field are animal studies which, unfortunately, have yielded inconsistent results. For example, it was shown that lowering serotonergic function can either impair, facilitate or have no effect on memory functions in rats (Altman and Normile, 1988; Sirvio et al., 1994). These discrepancies, which possibly originate from inconsistencies in timing and selectivity of the serotonergic manipulation and type of tests used, make it extremely difficult to reach a uniform conclusion about the role of 5-HT in cognitive functioning. After reviewing the data, McEntee and Crook (1991) concluded that, in general, findings indicate an inhibitory effect of 5-HT on memory functions. In contrast, based on animal experiments, Richter-Levin and Segal (1996) concluded that reduced serotonergic modulation in the hippocampus contributes to age-associated memory deficits.

The relationship between 5-HT and cognition is particularly relevant in those illnesses in which cognitive deficits occur along with changes in 5-HT activity. For example, diminished serotonin levels have been found in postmortem studies of patients with Alzheimer's disease (AD) (Altman and Normile, 1988; Cross, 1990; Bierer et al., 1995). Decreased serotonergic activity may underlie the cognitive deficits in AD (Richter-Levin and Segal, 1993), although it has been suggested that these 5-HT changes relate more closely to the non-cognitive changes associated with the disease, such as aggression (Palmer and DeKosky, 1993). In addition, depressed patients, in whom presumably 5-HT function is lowered, often show diminished cognitive capabilities (Burt et al., 1995). Treatment with 5-HT re-uptake inhibitors, which increase serotonergic transmission, often results in improvement of cognitive performance. However, since this improvement coincides with relief of the depression, it is not clear whether these cognitive changes are directly due to altered 5-HT function or are secondary to the alleviation of the depression itself. In healthy human volunteers, administration of 5-HT re-uptake inhibitors in general does not affect cognitive performance (Thompson, 1991; Amado-Boccara et al., 1995).

One method to study serotonergic function in humans is acute tryptophan depletion (ATD) (for a review, see Reilly et al., 1997). This manipulation causes a temporary global reduction of 5-HT synthesis in the brain by decreasing the availability of the 5-HT precursor L-tryptophan (Trp) in the brain (Young et al., 1985). Oral administration of Trp-free amino acid mixture stimulates protein synthesis, thereby clearing Trp from the blood. Second, it reduces the transport of plasma Trp into the brain by increasing the amount of large neutral amino acids (LNAA) which compete with Trp for the active transport sites across the blood-brain barrier. Administration of $100 \mathrm{~g}$ of a Trp-free amino acid mixture has been 
shown to cause a significant lowering of 5-HT synthesis throughout the brain after $5 \mathrm{~h}$ in healthy human subjects (Nishizawa et al., 1997).

To date, few studies have focussed on the effects of ATD on cognitive performance in normal human subjects. Park et al. (1994) reported impairment of learning and retrieval functions after ATD, whereas Coull et al. (1995) found some positive effects of ATD, in that it speeded the response to incompatible stimuli. Recently, it was found that ATD impaired long-term memory consolidation in a word learning task. This effect was highly specific since no effect was seen on short-term memory function or performance on perceptual and psychomotor tasks (Riedel et al., 1999). Since memory for words was impaired 30 min after their presentation, and although a small non-significant additional decrement was seen $18 \mathrm{~h}$ later, the authors concluded that ATD most probably interfered with memory consolidation primarily during the first $30 \mathrm{~min}$ after acquisition.

The present study was designed to further investigate the specific effects of ATD on memory functions. If indeed ATD disrupts memory consolidation primarily within $30 \mathrm{~min}$ after acquisition, the induction of ATD after this 30-min period should not influence subsequent memory performance. To test this hypothesis, we induced ATD $1 \mathrm{~h}$ after presentation of a word list (post-learning) and measured free recall and recognition for these words $5 \mathrm{~h}$ after their presentation. We hypothesized that ATD would have no effect on memory performance at this time. Conversely, when ATD is induced $4 \mathrm{~h}$ before presentation of a new word list (pre-learning), we would expect impaired long-term memory retention $30 \mathrm{~min}$ after that presentation, without an effect on immediate recall. Furthermore, no additional decrement in memory performance would be expected when tested $4 \mathrm{~h}$ after presentation of these words.

The second objective of this study was an exploration of the effects of ATD over a wide range of cognitive functions. To this end, we included several neuropsychological tests which assess attentional, memory and psychomotor functions in the cognitive test battery. Since cognitive performance can depend on mood state, and ATD may affect mood (Ellenbogen et al., 1996), this may be a confounding factor. To control for this potential confound, we included two visual analogue mood scales in the experiment.

\section{Materials and methods}

\section{Subjects}

Twenty healthy subjects (10 male, 10 female) were recruited through advertisements within the university. The subjects were aged 20-29 years (mean 23.3 years, SD 2.6 years). Physical and mental health of each subject was assessed by means of a health questionnaire, medical examination, and routine electrocardiogram and urine screening. Excluded were those volunteers who suffered from, or had a history of, cardiac, hepatic, renal, pulmonary, neurological, gastrointestinal, haematological or psychiatric illness. Other exclusion criteria were excessive drinking (> 20 units of alcohol a week) pregnancy or lactation, use of medication other than oral contraceptives, smoking, use of drugs, and any sensory or motor deficits which could reasonably be expected to affect test performance. None of the subjects had a family history of depression, as was established by an interview. The study was approved by the Medical Ethics Committee of Maastricht
University and the Maastricht University Hospital's Board of Directors. All subjects gave their written informed consent prior to participation.

\section{Design}

The study was conducted according to a placebo-controlled, double-blind, crossover design. The treatment consisted of administration of a placebo or a Trp deletion mixture (ATD) (see below). Treatment order was balanced over the two test days, which were at least 7 days apart.

\section{Amino acid mixtures}

The ATD amino acid mixture (100 g) consisted of 15 amino acids in the following composition: $5.5 \mathrm{~g}$ L-alanine, $3.2 \mathrm{~g}$ glycine, $3.2 \mathrm{~g}$ L-histidine, $8.9 \mathrm{~g}$ L-lysine, $12.2 \mathrm{~g}$ L-proline, $6.9 \mathrm{~g}$ L-serine, $6.5 \mathrm{~g} \mathrm{~L}-$ threonine, $4.9 \mathrm{~g}$ L-arginine, $2.7 \mathrm{~g} \mathrm{~L}$-cysteine and $3.0 \mathrm{~g} \mathrm{~L}$ methionine; LNAAs: $8.0 \mathrm{~g}$ L-isoleucine, $13.5 \mathrm{~g}$ L-leucine, $5.7 \mathrm{~g} \mathrm{~L}$ phenylalanine, 6.9 L-tyrosine, $8.9 \mathrm{~g}$ L-valine.

Reduced $\operatorname{Trp} / \Sigma$ LNAA ratios were reported after a placebo mixture containing $2.3 \mathrm{~g}$ (Wolfe et al., 1995) and $3.0 \mathrm{~g} \mathrm{~L}$ tryptophan (Riedel et al., 1999), and this may underestimate the effect of tryptophan depletion. In order to maintain a constant Trp/ $\Sigma$ LNAA ratio during the control condition, the amount of Ltryptophan in the placebo mixture was increased to $4.6 \mathrm{~g}$. After a comparison of various control mixtures, Welzin et al. (1994) found this mixture to be neutral with regard to the Trp/LLNAA ratio.

To provide caloric energy until lunchtime, approximately $20 \mathrm{~g}$ of a maltodextrin (MD)/fat mixture (33\% sunflower oil and $67 \%$ MD) was added to the amino acid mixture. Amino acid drinks were prepared prior to administration by adding $300 \mathrm{ml}$ tap water to the amino acid-MD/fat mixture. To compensate for the unpalatable taste, the mixture was flavoured with either strawberry or banana food flavouring. The amino acid mixtures were administered in two portions. The main portion of $90 \mathrm{~g}$ was given at $t_{0}$. Subjects were instructed to finish their consumption as fast as possible, but at least within $2 \mathrm{~h}$. A second portion of $10 \mathrm{~g}$ amino acid mixture, which functioned as a maintenance dose, was administered $6 \mathrm{~h}$ later $\left(t_{6}\right)$.

\section{Procedure}

All subjects underwent one complete training session to minimize learning effects. During this training session, the entire test battery was completed by each subject. On each test day the subjects arrived at the laboratory at 08.30 hours, after an overnight fast. Subjects were instructed not to use alcohol on the day prior to the experiment, and to arrive well-rested. Figure 1 shows a schematic overview of a test day. During the test day, the cognitive test battery (see below) was completed three times: $1 \mathrm{~h}$ before administration of the AA mixture (baseline, $t_{0}$ ) and 5 and $9 \mathrm{~h}$ after the AA mixture $\left(t_{5}\right.$ and $\left.t_{9}\right)$. Each cognitive test battery was preceded by a mood evaluation and followed by blood sampling. Between measurements the subjects remained in a room where they could watch videos, read magazines or books, or play board games. Water, decaffeinated coffee and tea, diet soft drinks (but not cola), oranges, apples, grapes and protein-free candy were available ad libitum. Subjects were served a protein-poor lunch and dinner. After completion of the test day, bananas and pineapple chunks, which are a rich natural source of L-tryptophan, were served to facilitate a quick recovery from possible incapacitating effects of ATD. 


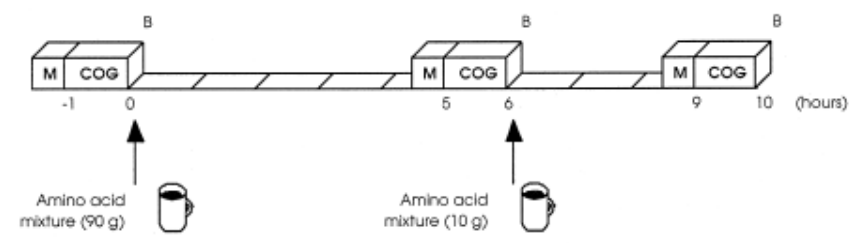

Figure 1 Schematic representation of a test day. COG, cognitive test battery; M, mood scales; B, blood sample

\section{Cognitive assessment}

The cognitive test battery took approximately $50 \mathrm{~min}$ to complete. For each of the assessments, one of six parallel versions of the cognitive tests were used, except for the Stroop Colour Word Test and Motor Choice Reaction Time. The six parallel versions were balanced over two test days using a $6 \times 6$ Latin square. A separate parallel version of each test was used for the training sessions.

\section{The Visual Verbal Learning Test (VVLT)}

This test is an adapted version of the Auditory Verbal Learning Test (Rey, 1964). Thirty words are presented in the same sequence in three trials on a computer screen. Each trial ends with a free recall of the words (immediate recall). Thirty minutes after the first trial, the subject is requested to recall as many words as possible (delayed recall). This is followed by a recognition test, consisting of 15 previously presented words and 15 other but comparable words, in which the subject has to respond 'Yes/No' as quickly as possible to indicate recognition of the word (delayed recognition). The proportion of correctly recognized words $(c r)$ and the proportion of falsely recognized $(f r)$ constitute the nonparametric sensitivity measure: $A^{\prime}=1-1 / 4[f r / c r+(1-c r) /(1-f r)]$ (Pollack and Norman, 1964). $A^{\prime}$ is in fact the proportion of correctly recognized words, corrected for the subject's response tendency. $A^{\prime}$ is arcsin transformed before being entered into statistical analysis because of its skewed distribution.

In this study, word lists were presented at $t_{0}, t_{5}$ and $t_{9}$. After $t_{0}$, delayed recall and recognition were assessed twice: once after a delay of $30 \mathrm{~min}\left(t_{0 \rightarrow 0}\right)$ and once after a delay of $5 \mathrm{~h}\left(t_{0 \rightarrow 5}\right)$. Similarly, for the word list presented at $t_{5}$, delayed recall and recognition were assessed after $30 \min \left(t_{5 \rightarrow 5}\right)$ and again after $4 \mathrm{~h}$ $\left(t_{5 \rightarrow 9}\right)$. Delayed recall and recognition for the word list presented at $t_{9}$ was assessed only once, after a delay of $30 \mathrm{~min}\left(t_{9 \rightarrow 9}\right)$.

Outcome variables were the maximum number of words recalled in either of the three immediate recall trials as a measure of short-term memory, the number of correct words on the delayed recall as a measure of retrieval from long-term memory, sensitivity measure $\left(A^{\prime}\right)$ as a measure of storage in long-term memory, and median reaction time of correctly recognized target words as a measure of speed of retrieval from long-term memory.

Verbal Fluency Test (Luteijn and van der Ploeg, 1983)

The fluency test can be regarded as a measure of strategy-driven retrieval of information from semantic memory. The subjects are asked to produce as many four-letter words as possible starting with a given letter, within $1 \mathrm{~min}$. The number of correct responses and errors are recorded. Nonsense words were not accepted, but names, conjugations and plurals were allowed. Starting letters were $\mathrm{B}, \mathrm{H}, \mathrm{R}, \mathrm{L}, \mathrm{P}$ and $\mathrm{M}$. These letters yielded a high and similar number of correct responses (average: 10.1-11.0 words) in a comparative study with 40 subjects (Houx, unpublished data).
Stroop Colour Word Test (SCWT) (Stroop, 1935)

The SCWT has often been used to test focussed attention. The test consists of three subtests. First, a card with a hundred colour names must be read as quickly as possible, followed by a subtest in which the same number of coloured patches must be named. In the third subtest, colour names are printed in incongruously coloured ink. The colour of the ink must be named, without paying attention to the word itself. The outcome parameters of this test are the time needed to complete each subtest and the interference measure. The latter denotes the percentage of extra time needed to complete card III, relative to the average of card I and II: (time card III/[(time card I + time card II)/2)] $\times 100 \%$.

\section{Dichotic listening task}

Dichotic listening can be used to test both focussed attention and divided attention for auditory stimuli. Subjects receive two different auditory stimuli simultaneously though a stereo headphone, one stimulus on each side. The stimuli are numbers ranging from 1 to 200, presented at random and natural-speech spoken by a male voice. This version of the test consists of three subtasks in which subjects are instructed to focus on either the right channel, the left channel or on both channels, and to remember these numbers. The subtasks in which subjects must focus on one side, while ignoring the other, can be regarded as a focussed attention task. The subtask in which stimuli from both sides have to be remembered is a divided attention task. Each of the three subtasks is made up of nine trials, in which two, three or four stimuli pairs are presented in random order. After each trial, the subjects must identify the appropriate numbers from a list of numbers on a computer screen. This list is composed of all presented numbers, plus the same amount of other numbers. Outcome variables are the total number of correctly identified stimuli, total number of stimuli identified from the wrong side, and number of false alarms (numbers which were not presented). Performance on each subtask is assessed by calculating sensitivity measures, similar to those used in the VVLT.

\section{Tower of London (Shallice, 1982)}

The Tower of London is a test of planning. The test consists of three coloured balls which must be arranged on three sticks to match a picture with the goal positions. The complexity of the problem is altered by varying the minimum number of moves to reach the goal positions. Each trial consisted of a two- to sevenmove problem. Prior to each problem, the subjects are informed about the minimum number of moves in which the problem can be solved. The number of moves, time to solve the problem, and time between presentation of the goal positions and the first move (decision time), are recorded. For the Tower of London no baseline measures were taken.

\section{Symbol Digit Modalities Test (SDMT) (Smith, 1968)}

This test is an often-used measure of the speed of processing of general information. This version of the SDMT consists of five rows containing, in all, 75 blank squares, each paired with a randomly assigned symbol. Above these rows is a printed key that pairs each of the nine different symbols with a number from 1 to 9 . The task is to write down the corresponding number in the blank square below each symbol as quickly as possible. Each test is preceded by a practice trial on the first 10 blank squares. The time 
required to fill the remaining 65 blank spaces and the number of errors are recorded.

\section{Motor Choice Reaction Time (MCRT) (Houx and Jolles, 1993)}

Speed of information processing was assessed by measuring reaction times (RTs) as a function of task complexity. The test consists of a simple, choice and incompatible RT test. This yields RTs consisting of an initiation phase (time from stimulus onset until release of a hold button) and a movement phase (time from release of the hold button until the response button is pushed). The measures used for analysis are the median initiation RTs of the simple, the choice and the incompatible condition and the overall median movement RTs.

\section{Mood scales}

Mood was assessed using 'Bond and Lader Visual Analogue Scales' (Bond and Lader, 1974) and a visual analogue version of the shortened Dutch 'Profile of Mood States' (POMS) (McNair et al., 1971).

\section{Blood samples}

Blood $(10 \mathrm{ml})$ was collected by venipuncture in sodium heparin tubes. Blood samples were placed on ice immediately after collection, and centrifuged at $4{ }^{\circ} \mathrm{C}(5 \mathrm{~min}$ at 5000 r.p.m.) within $30 \mathrm{~min}$. Subsequently, $100 \mu \mathrm{l}$ plasma was mixed with $4 \mathrm{mg}$ sulfasalicyl acid, frozen in liquid nitrogen and stored at $-80{ }^{\circ} \mathrm{C}$ until quantitative amino acid analysis by high-performance liquid chromatography (Van Eijk et al., 1993).

\section{Statistical analysis}

\section{Primary cognitive outcome measure: VVLT}

Dependent variables of the delayed recall and recognition assessments of the word lists presented at $t_{0}$ and $t_{5}$ were analysed separately using a repeated measure analysis of variance (MANOVA, SPSS 6.1 for Macintosh, SPSS Inc, Chicago, IL, USA). Within subjects factors were time of the recall and recognition assessments of each word list $\left(t_{0 \rightarrow 0}\right.$ and $t_{0 \rightarrow 5}$ for the word list at $t_{0}$, and $t_{5 \rightarrow 5}$ and $t_{5 \rightarrow 9}$ for the word list presented at $t_{5}$ ), and treatment (placebo, ATD). Immediate recall at $t_{0}, t_{5}$ and $t_{9}$, and delayed recall and recognition assessments at $t_{9}$ were analysed using treatment as a within-subjects factor. Sex was entered as a between-subjects factor. Since these comparisons were planned, based on previous findings (Riedel et al., 1999), no correction for multiple comparisons was made.

Secondary cognitive outcome measures, mood scales and blood parameters

Dependent variables were analysed separately in a repeated measures multivariate analysis of (co)variance, according to a 2 (treatment: placebo, ATD) $\times 2$ (time: $t_{5}, t_{9}$ ) factorial model to test the main effect of treatment, time and the treatment by time interaction, using baseline scores $\left(t_{0}\right)$ as covariates. Sex was entered as a between-subjects factor. In case of a treatment by time interaction, the differences between pairs of treatment conditions at $t_{5}$ and $t_{9}$ were examined using paired $t$-tests (ATD versus placebo, after correction for baseline scores).

Initially, order of treatment was included as a between-subjects factor in the analysis. However, since none of the primary outcome parameters showed an effect of treatment order or an order interaction with treatment, and since treatment order only influenced the effect of ATD in four of the 32 parameters (Stroop card III, Dichotic Listening 'right', Tower of London total time and number of steps), this factor was not considered in the remaining analyses.

\section{Results}

Seventeen subjects ( 9 males, 8 females) completed the study. Three subjects withdrew from the study on the first test day due to adverse effects of the AA mixture, particularly gastrointestinal discomfort. Two of these subjects (one male and one female) were in the ATD condition, and one female was in the placebo condition.

\section{Primary outcome measures}

The results of the delayed recall and recognition trials are depicted in Fig. 2, immediate recall scores and delayed recognition reaction times are listed in Table 1.
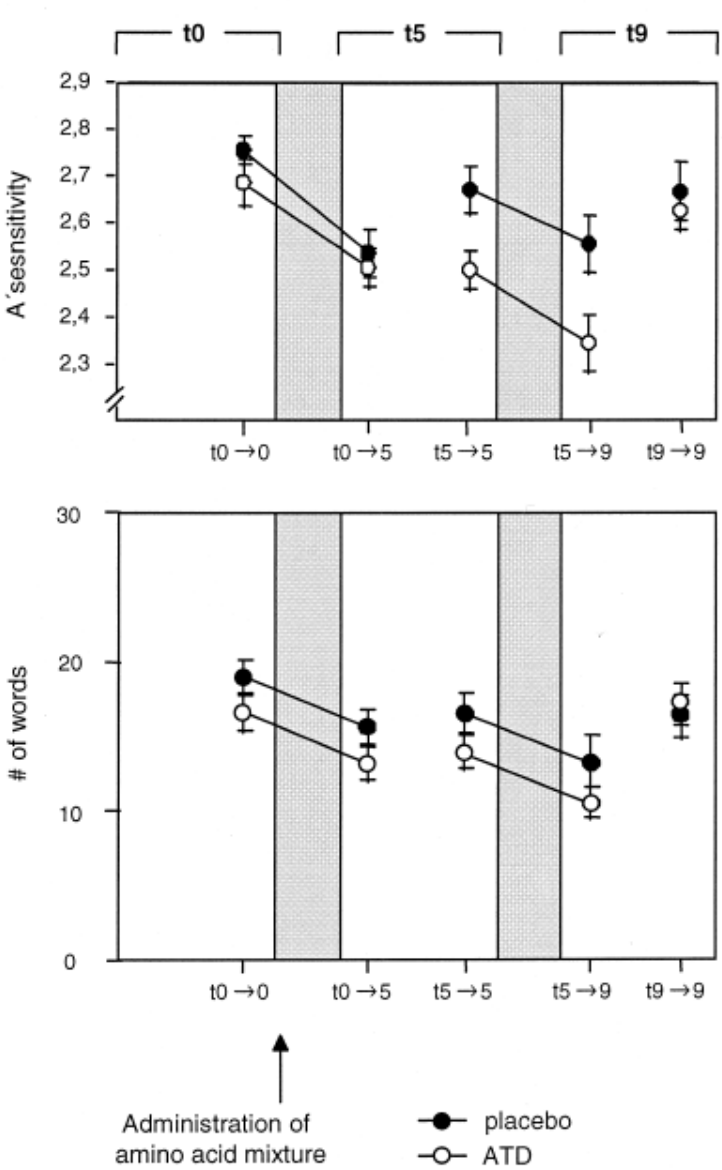

Figure 2 Means $( \pm \mathrm{SE})$ of the delayed recall and delayed recognition assessments of the VVLT at baseline $\left(t_{0}\right)$ and at $5\left(t_{5}\right)$ and $9 \mathrm{~h}\left(t_{9}\right)$ after administration of the AA mixture. Delayed recognition performance is depicted in the top box, delayed recall in the lower box. $X$-axis labels $t_{\mathrm{x} \rightarrow \mathrm{y}}$ denote time of word list presentation (x) and time of assessment (y) 
Table 1 Means (SE) of the immediate recall and delayed recognition reaction time of the VVLT

\begin{tabular}{|c|c|c|c|c|c|c|c|c|c|c|c|}
\hline \multirow{2}{*}{$\begin{array}{l}\text { Measure } \\
\text { Immediate recall (No. words) }\end{array}$} & \multirow{3}{*}{$\begin{array}{l}\text { Treatment } \\
\text { Placebo } \\
\text { ATD }\end{array}$} & \multicolumn{2}{|c|}{$t_{0 \rightarrow 0}$} & \multicolumn{2}{|c|}{$t_{0 \rightarrow 5}$} & \multicolumn{2}{|c|}{$t_{5 \rightarrow 5}$} & \multicolumn{2}{|c|}{$t_{5 \rightarrow 9}$} & \multicolumn{2}{|c|}{$t_{9 \rightarrow 9}$} \\
\hline & & 51.2 & $(2.0)$ & & & 47.1 & $(2.8)$ & & & 48.7 & (2.9) \\
\hline & & 46.1 & $(1.9)$ & & & 43.1 & $(2.8)$ & & & 49.1 & $(2.5)$ \\
\hline \multirow[t]{2}{*}{ Recognition RT (ms) } & Placebo & 621 & (12) & 640 & (19) & 634 & (24) & 653 & $(22)$ & 638 & (17) \\
\hline & ATD & 658 & (33) & 646 & (30) & 661 & (23) & 663 & (23) & 641 & (20) \\
\hline
\end{tabular}

Column headings $t_{\mathrm{x} \rightarrow \mathrm{y}}$ denote the time of presentation of the word list (x) and time of assessment (y).

\section{VVLT: word list presented at to}

The ATD group had a significantly lower immediate recall performance before start of the treatment $[F(1,15)=4.88$, $p<0.05]$. Delayed recall showed a main effect of treatment $[F(1,15)=5.41, p<0.05]$ and a main effect of time $[F(1,15)=140.96, p<0.001]$. Delayed recall in the ATD group was significantly lower than that of the placebo group. Note however, that ATD was not induced until after delayed recall at $t_{0}$ $\left(t_{0 \rightarrow 0}\right)$. Therefore, effects of ATD can only be observed at $t_{5}\left(t_{0 \rightarrow 5}\right)$ and not at $t_{0}\left(t_{0 \rightarrow 0}\right)$. Consequently, an actual effect of ATD should generate an interaction between treatment and time. No treatment by time interaction was found however $[F(1,15)=0.00$, NS $]$, indicating that the induction of ATD had no effect on delayed recall at $t_{5}\left(t_{0 \rightarrow 5}\right)$. Delayed recognition performance was only affected by time $[F(1,13)=15.83, p<0.01]$, and not by treatment $[F(1,15)=1.15, \mathrm{NS}]$, nor was there a treatment by time interaction $[F(1,15)=0.20, \mathrm{NS}]$. Reaction times of the delayed recognition showed no effects of treatment $[F(1,15)=0.72$, NS $]$, time $[F(1,15)=0.00, \mathrm{NS}]$ or a treatment by time interaction $[F(1,15)=1.65, \mathrm{NS}]$.

\section{VVLT: word list presented at $t_{5}$}

Treatment did not affect immediate recall performance at $t_{5}$ $[F(1,15)=3.10, \mathrm{NS}]$. Delayed recall of the word list presented at $t_{5}$ showed a main effect of treatment $[F(1,15)=6.03, p<0.05]$. Delayed recall was impaired during ATD. A main effect of time $[F(1,15)=39.05, p<0.001]$ showed that delayed recall performance at $t_{9}\left(t_{5 \rightarrow 9}\right)$ was lower than at $t_{5}\left(t_{5 \rightarrow 5}\right)$. No interaction between treatment and time was seen $[F(1,15)=0.03$, NS $]$, indicating that ATD did not cause additional impairment at the $t_{5 \rightarrow 9}$ recall assessment compared to the $t_{5 \rightarrow 5}$ assessment. Similar results were seen for delayed recognition sensitivity: a main effect of treatment $[F(1,14)=8.98, p<0.01]$ and time $[F(1,14)=13.71$, $p<0.01])$, and no treatment by time interaction $[F(1,14)=0.69$, NS]. Reaction times of the delayed recognition were only affected by time $[F(1,14)=6.14, p<0.05]$, but not by treatment $[F(1,14)=0.00, \mathrm{NS}]$, and no treatment by time interaction was found $[F(1,14)=0.05$, NS $]$.

\section{VVLT: word list presented at t9}

Immediate recall at $t_{9}$ was not affected by treatment $[F(1,15)=0.04, \mathrm{NS}]$. Also, no treatment effect was seen for delayed recall $[F(1,15)=0.28, \mathrm{NS}]$, delayed recognition sensitivity $[F(1,15)=0.21, \mathrm{NS}]$ or delayed recognition reaction times $[F(1,15)=0.00, \mathrm{NS}]$ of the word list presented at $t_{9}$.

\section{Secondary outcome measures}

The results of the secondary cognitive assessments and details of the repeated measures analyses are listed in Table 2.

\section{Fluency test}

For one subject, baseline data were not available. A treatment by time interaction was present for the number of words produced on the fluency test. Subsequent paired $t$-test analyses revealed that more words were produced in the ATD condition compared to the placebo condition $\left(t_{15}=-2.49, p<0.05\right)$, but this treatment effect was present only at $t_{5}$ and not at $t_{9}$.

\section{Stroop Colour Word Test}

A main effect of treatment was seen on the interference measure of the Stroop test. Subjects in the ATD condition showed less interference compared to the placebo condition. In addition, a main effect of time was present on this measure, with less interference at $t_{5}$ compared to $t_{9}$. Improved performance during the ATD condition was also seen for card II and card III. Performance on card I was not affected by treatment, but showed main effect of time, with an improvement at $t_{9}$ compared to $t_{5}$. None of the outcome measures had a treatment by time interaction, and no effects were seen on the number of errors made on each subtask.

\section{Dichotic listening task}

Performance on subtask 'right' was significantly improved in the ATD condition. The same effect appeared to be present for subtask 'left', but this was not statistically significant. Performance on subtask 'both' did not differ between treatment conditions and none of the subtasks showed main effects of time effects or treatment by time interactions.

\section{Tower of London}

Two subjects (ATD/placebo) were excluded from the analyses of all the Tower of London parameters because of missing data. Data were also missing for an additional three subjects (one ATD, one placebo and one in both conditions) for decision time and for one subject (ATD) for total time and total number of moves. Total number of moves did not differ between treatment conditions or test times, and no time by treatment interaction was present. Total time to solve the problems was only affected by time but not by treatment, and no treatment by time interaction was found. Decision time was not affected by treatment or time. A treatment by time interaction was found, however, for the decision time. At $t_{5}$, decision time was shorter for the subjects in the ATD condition compared to the placebo condition $\left(t_{12}=2.46, p<0.05\right)$, but this effect was not present at $t_{9}$.

\section{Symbol Digit Modalities Test}

Performance on the SDMT was not affected by treatment or time, and no treatment by time interaction was found.

\section{Motor Choice Reaction Time}

Overall movement time showed a main effect of time. Otherwise, no effects were seen on the outcome variables of the MCRT. 

measures analyse

\begin{tabular}{|c|c|c|c|c|c|c|c|c|c|}
\hline \multirow[b]{2}{*}{ Measure } & \multicolumn{2}{|c|}{$t_{0}$} & \multicolumn{2}{|c|}{$t_{5}$} & \multicolumn{2}{|c|}{$t_{9}$} & \multirow[b]{2}{*}{ Treatment } & \multirow[b]{2}{*}{ Time } & \multirow{2}{*}{$\begin{array}{l}\text { Treatment } \\
\text { by time }\end{array}$} \\
\hline & Placebo & ATD & Placebo & ATD & Placebo & ATD & & & \\
\hline \multicolumn{10}{|l|}{ Fluency } \\
\hline No. of words correct & $14.2(1.0)$ & $12.8(1.0)$ & $13.4(0.7)$ & $15.6(0.8)$ & $15.8(1.0)$ & $15.0(1.0)$ & $F(1,13)=2.06$ & $F(1,14)=2.18$ & $F(1,14)=4.82 *$ \\
\hline \multicolumn{10}{|l|}{$S C W T$} \\
\hline Time card I (s) & $35.2(1.2)$ & $35.0(1.1)$ & $35.7(1.1)$ & $35.1(1.2)$ & $34.7(1.1)$ & $33.8(1.0)$ & $F(1,14)=2.97$ & $F(1,15)=20.19 \ddagger$ & $F(1,15)=0.31$ \\
\hline Time card II (s) & $44.6(1.9)$ & 44.4 (1.6) & $43.8(1.8)$ & $42.0(1.4)$ & $43.6(1.7)$ & $42.2(1.5)$ & $F(1,14)=7.49 *$ & $F(1,15)=0.00$ & $F(1,15)=0.36$ \\
\hline Time card III (s) & $64.4(3.5)$ & $63.5(3.2)$ & $61.4(3.1)$ & $56.5(2.7)$ & $62.5(2.8)$ & $58.1(2.8)$ & $F(1,14)=17.83$ & $F(1,15)=3.33$ & $F(1,15)=0.06$ \\
\hline Interference $(\%)$ & $60.5(5.1)$ & $59.0(4.8)$ & $54.4(5.4)$ & $46.1(4.5)$ & $60.0(5.7)$ & $52.4(4.3)$ & $F(1,14)=6.09^{*}$ & $F(1,15)=6.94 *$ & $F(1,15)=0.02$ \\
\hline \multicolumn{10}{|l|}{$D L T$} \\
\hline Left side sensitivity (\%) & $88.9(1.9)$ & $90.7(1.4)$ & $90.3(1.2)$ & $92.7(1.3)$ & $91.4(1.6)$ & $93.5(1.5)$ & $F(1,14)=3.28$ & $F(1,15)=1.23$ & $F(1,15)=0.12$ \\
\hline Right side sensitivity (\%) & $93.3(1.2)$ & $92.5(1.2)$ & $92.2(1.4)$ & $95.4(0.8)$ & $93.7(0.9)$ & $94.8(1.0)$ & $F(1,14)=5.17^{*}$ & $F(1,15)=0.04$ & $F(1,15)=0.69$ \\
\hline Both sides sensitivity (\%) & $83.6(0.9)$ & $83.1(1.1)$ & $83.8(1.0)$ & $84.6(0.8)$ & $84.0(1.3)$ & $83.9(0.9)$ & $F(1,14)=0.86$ & $F(1,15)=0.10$ & $F(1,15)=0.04$ \\
\hline \multicolumn{10}{|l|}{$M C R T$} \\
\hline Simple RT (ms) & $277(6)$ & $283(7)$ & $270(5)$ & $270(6)$ & $269(5)$ & $272(5)$ & $F(1,14)=0.07$ & $F(1,15)=0.03$ & $F(1,15)=0.42$ \\
\hline Choice RT (ms) & $317(5)$ & $329(8)$ & $315(5)$ & $324(9)$ & $314(5)$ & $317(6)$ & $F(1,14)=0.57$ & $F(1,15)=0.65$ & $F(1,15)=1.73$ \\
\hline Incompatible RT (ms) & $393(11)$ & $409(17)$ & $379(12)$ & $395(16)$ & $383(13)$ & $400(18)$ & $F(1,14)=0.95$ & $F(1,15)=0.57$ & $F(1,15)=0.00$ \\
\hline Movement (ms) & $102(4)$ & $103(4)$ & $104(4)$ & $100(4)$ & $100(4)$ & $98(4)$ & $F(1,14)=3.33$ & $F(1,15)=6.54^{*}$ & $F(1,15)=0.04$ \\
\hline \multicolumn{10}{|l|}{$S D M T$} \\
\hline \multicolumn{10}{|l|}{ TOL } \\
\hline Decision time (s) & - & - & $45.6(6.3)$ & $37.5(3.5)$ & $37.7(4.3)$ & $38.1(4.6)$ & $F(1,10)=2.67$ & $F(1,10)=0.26$ & $F(1,10)=7.44^{*}$ \\
\hline Total time (s) & - & - & $122.1(9.1)$ & $109.6(9.5)$ & $108.1(7.1)$ & $99.5(4.8)$ & $F(1,12)=0.80$ & $F(1,12)=7.71 *$ & $F(1,12)=0.20$ \\
\hline Total no. of moves & - & - & $36.8(2.0)$ & $35.5(1.9)$ & $35.5(1.5)$ & $34.0(1.5)$ & $F(1,12)=0.38$ & $F(1,12)=1.55$ & $F(1,12)=0.07$ \\
\hline \multicolumn{10}{|l|}{ POMS } \\
\hline Depression & $0.95(0.11)$ & $0.92(0.11)$ & $0.96(0.13)$ & $0.93(0.12)$ & $0.86(0.14)$ & $0.87(0.12)$ & $F(1,14)=0.06$ & $F(1,15)=2.25$ & $F(1,15)=0.04$ \\
\hline Anger & $0.91(0.10)$ & $0.93(0.10)$ & $0.86(0.08)$ & $0.96(0.12)$ & $0.83(0.13)$ & $0.85(0.11)$ & $F(1,14)=0.34$ & $F(1,15)=3.40$ & $F(1,15)=0.16$ \\
\hline Fatigue & $1.33(1.67)$ & $1.38(0.19)$ & $1.48(0.16)$ & $1.50(0.15)$ & $1.24(0.13)$ & $1.57(0.19)$ & $F(1,14)=0.59$ & $F(1,15)=0.56$ & $F(1,15)=3.38$ \\
\hline Tension & $0.98(0.12)$ & $0.97(0.15)$ & $0.76(0.11)$ & $0.93(0.12)$ & $0.79(0.13)$ & $0.80(0.13)$ & $F(1,14)=0.95$ & $F(1,15)=1.90$ & $F(1,15)=2.60$ \\
\hline Vigor & $1.33(0.18)$ & $1.31(0.16)$ & $1.53(0.17)$ & $1.52(0.17)$ & $1.02(0.13)$ & $1.50(0.19)$ & $F(1,14)=1.05$ & $F(1,15)=4.67^{*}$ & $F(1,15)=13.37$ \\
\hline \multicolumn{10}{|l|}{ Bond and Lader } \\
\hline Contentedness & $7.41(0.26)$ & $6.84(0.28)$ & $7.41(0.30)$ & $7.22(0.34)$ & $7.49(0.38)$ & $7.58(0.35)$ & $F(1,14)=0.12$ & $F(1,15)=1.60$ & $F(1,15)=1.18$ \\
\hline Calmness & $7.67(0.30)$ & $7.56(0.30)$ & $7.52(0.36)$ & $7.35(0.43)$ & $8.05(0.35)$ & $7.69(0.44)$ & $F(1,14)=1.45$ & $F(1,15)=2.18$ & $F(1,15)=4.42$ \\
\hline Alertness & $7.09(0.43)$ & $6.58(0.39)$ & $6.69(0.39)$ & $6.56(0.43)$ & $7.35(0.37)$ & $6.51(0.46)$ & $F(1,14)=1.33$ & $F(1,15)=2.48$ & $F(1,15)=0.17$ \\
\hline
\end{tabular}

$* p<0.05, \dagger p<0.01, \ddagger p<0.001$. SCWT, Stroop Colour Word Test; DLT, dichotic listening task; MCRT, Motor Choice Reaction Time, SDMT, Symbol Digit Modalities Test; TOL, Tower of London; POMS, Profile of Mood States. 


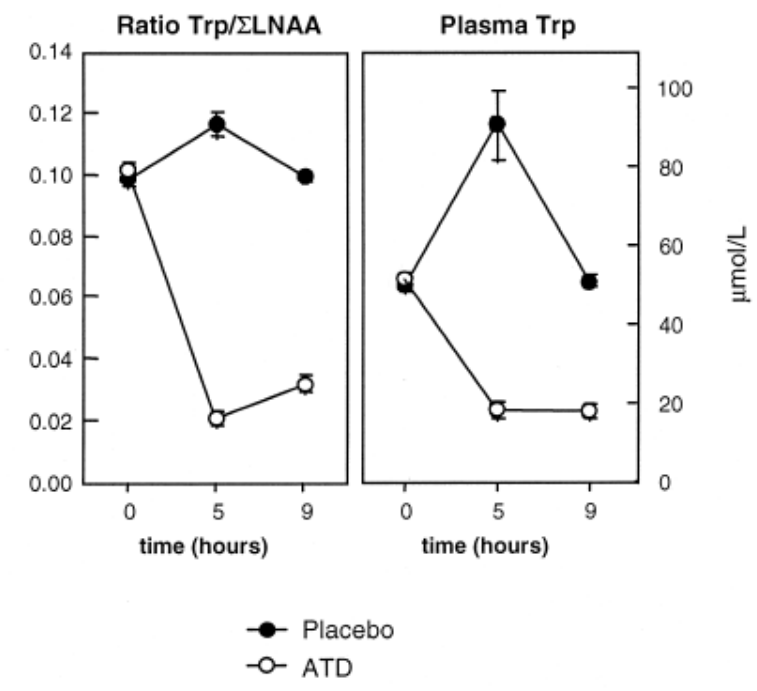

Figure 3 Mean $( \pm$ SE) plasma ratio Trp/ 2 LNAA and plasma Trp levels at baseline $\left(t_{0}\right)$ and $5\left(t_{5}\right)$ and $9\left(t_{9}\right)$ h after start of the treatment

\section{Mood scales}

The results of the mood assessments are summarized in Table 2. None of the scales of the POMS (depression, anger, tension, fatigue or vigour) or Bond and Lader (contentedness, calmness, alertness) showed a main effect of treatment. The POMS vigour scale showed main effect of time and a treatment by time interaction. At $t_{9}$ (but not at $t_{5}$ ), subjects in the ATD condition reported to feel more vigourous.

\section{Plasma amino acid levels}

Plasma Trp concentrations and the Trp/LLNAA ratios in the placebo and ATD condition at the three assessments are depicted in Fig. 3. No blood samples could be obtained for one subject at $t_{0}$ (ATD) and one at $t_{9}$ (placebo), and invalid plasma leucine content prevented the calculation of the ratio Trp/ $\Sigma$ LNAA for one subject at $t_{5}$ (placebo). Analysis of plasma Trp levels showed a main effect of treatment $[F(1,12)=89.17, p<0.001]$, a main effect of time $[F(1,13)=24.87, p<0.001]$ and a treatment by time interaction $[F(1,13)=18.81, p<0.01]$. The ATD mixture caused a mean drop in plasma Trp concentrations of $63 \%$ at $t_{5}$, and $64 \%$ at $t_{9}$, relative to baseline values. In contrast, plasma Trp concentration in the placebo condition increased by $80 \%$ at $t_{5}$, but returned to baseline levels at $t_{9}$. Plasma ratio Trp/ $\Sigma$ LNAA showed a main effect of treatment $[F(1,11)=313.21, p<0.001]$, no main effect of time $[F(1,12=1.36, \mathrm{NS}]$, and treatment by time interaction $[F(1,12)=25.43, p<0.001]$. In the ATD condition, the plasma ratio $\operatorname{Trp} / \Sigma$ LNAA fell to $21 \%$ of baseline at $t_{5}$ and to $33 \%$ of baseline at $t_{9}$. The placebo mixture caused a $20 \%$ increase in ratio $\operatorname{Trp} / \Sigma$ LNAA at $t_{5}$ relative to baseline, but not at $t_{9}$.

\section{Sex differences}

No sex differences were present for the effects of ATD on cognitive measures, mood scales or blood parameters.

\section{Discussion}

The primary aim of this study was to investigate the effects of lowered 5-HT synthesis by ATD on memory functioning. It was hypothesized that ATD would lead to impaired long-term memory performance due to a disruption of memory consolidation during the first $30 \mathrm{~min}$ after acquisition of new information. Our data show that the induction of ATD $1 \mathrm{~h}$ after presentation of a word list (post-learning) did not affect long-term memory function. Both delayed recall and recognition of those words were not impaired when tested $5 \mathrm{~h}$ later, during a depleted state, indicating that both retrieval and storage were unaffected. This is consistent with the notion that ATD interferes with consolidation primarily within $30 \mathrm{~min}$ after acquisition. Although unfortunate, the initial values difference for the immediate recall and 30 min delayed recall does not essentially influence the results. Subsequently, we presented a new word list $5 \mathrm{~h}$ after ATD. ATD impaired both delayed recall and recognition of these words $30 \mathrm{~min}$ after their presentation. These effects were not due to impaired learning since no effects were seen on immediate recall. Although both recall and recognition of these words were still impaired when tested $4 \mathrm{~h}$ after presentation, no additional impairment was seen after this $4 \mathrm{~h}$ delay. It thus appears that the detrimental effect of ATD is located mainly in the period between immediate recall and 30 min delayed recall and recognition, ergo within $30 \mathrm{~min}$ after acquisition. The impairment is then preserved, but not augmented, over time.

Following this premise, memory tests which do not incorporate delayed assessment or do not require long-term storage of new information are likely to fail to detect memory effects of ATD. Park et al. (1994) reported a specific impairment of learning and retrieval processes after ATD. However, except for paired associates learning, where ATD increased the number of trials needed to learn the spatial locations, none of the memory tests showed an effect of ATD. These memory tests essentially required immediate retrieval or assessed autobiographical memory, and neither of the tests involved consolidation of newly learned material over a longer period of time.

Furthermore, it appears that the timing of the manipulation is important when investigating the role of serotonin in specific memory functions. Our data indicate that reducing central 5-HT activity during or immediately after acquisition would disrupt memory function, whereas a reduction of 5-HT activity preretention would not. The timing of the 5-HT manipulation and its cognitive effects have been an issue of debate in the literature on animal studies for several years. Based on their experiments with 5-HT antagonists in mice, Altman and Normile (1988) concluded that "pretrain antagonist administration may interfere with some postlearning memory process, only if the drugs were present during or immediately after acquisition'. However, as is generally the case with the studies on serotonin and cognition, the results on this matter are far from consistent. The induction of the 5-HT manipulation at different moments in time provides a method to discriminate between the specific effects of serotonin on different memory processes, e.g. learning, retrieval and consolidation. The application of this method in human studies, combined with more rapid serotonergic manipulations, is needed to further clarify the role of serotonin in memory functions.

As for the secondary cognitive assessments, the most striking outcome is the enhancement of focussed attention functions by ATD. Performance on the Stroop Test and the dichotic listening task was improved after ATD, thus showing that the effect occurred for visual as well as auditory stimuli. Findings suggesting a beneficial effect of ATD on focussed attention functions have been 
reported previously. Stroop performance was improved after ATD in schizophrenic patients (Rosse et al., 1992) and in normal subjects (Rowley et al., 1997). Coull et al. (1995) found that ATD speeded the response to incompatible stimuli by attenuating the interference caused by stimulus-response incongruity in a focussed attention task. However, to our knowledge, this study is the first to demonstrate that ATD enhances focussed attention for auditory stimuli as well. This independence of modality emphasizes the robustness of the effect and strengthens the suggestion that central processing rather than perception is augmented by ATD.

Planning functions were not affected by ATD, as reflected by an absence of effects in both accuracy and time needed to solve the problems of the Tower of London. It should be noted, however, that a substantial number of missing data and the lack of baseline values limited the statistical power of this test. Nevertheless, our results are consistent with those of Park et al. (1994), who found no evidence for an effect of Trp depletion on several tests assessing frontal lobe function, including the Tower of London, working memory and attentional set-shifting. In our study, tryptophan depletion reduced the decision time at $t_{5}$ without affecting the total time. It appears that subjects started to move the balls sooner but subsequently needed more time to think while moving the balls. This would be indicative of increased impulsivity, rather than an improvement in planning function itself. At $t_{9}$, these subjects may have applied a more cautious strategy, perhaps being aware of the consequences of an early start. In this study, however, we did find some evidence for ATD to affect frontal lobe functions. The verbal fluency test is known to be sensitive to frontal lobe dysfunction (Lezak, 1995) and performance on this test was improved during ATD, albeit only at $t_{5}$. Also, since the frontal cortex is involved in the process of focussed attention (Lezak, 1995), the positive effects of ATD on the S troop Test and dichotic listening task may well be due to frontal changes. Removal of the inhibitory actions of 5-HT on other neurotransmitter systems, e.g. dopamine, noradrenaline and acetylcholine, may be involved in this mechanism (Robbins, 1997).

The plasma AA analysis showed that a rapid depletion of plasma tryptophan was accomplished in all subjects. The effect of the addition of carbohydrates and fat to the AA mixture has been discussed by Riedel et al. (1999) and the MD/fat mix presumably does not alter the effects of ATD on brain Trp availability. The reduction in plasma Trp levels (63\%) and Trp/ $\Sigma$ LNAA ratio (79\%) at $t_{5}$ is somewhat modest compared to the other studies which typically achieve a $75 \%$, respectively, $90 \%$ reduction. In our study, subjects were allowed to spread the consumption of the AA drink over a $2 \mathrm{~h}$ period and this is likely to cause a more modest but prolonged state of depletion. Nevertheless, both plasma Trp levels

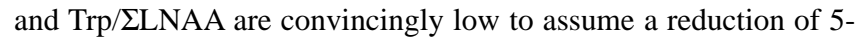
HT activity due to central tryptophan depletion. A neutral Trp/ $/$ LNAA ratio during the control condition was not accomplished by increasing the amount of Trp to $4.6 \mathrm{~g}$ in the placebo mixture. The placebo mixture produced a $20 \%$ rise in $\operatorname{Trp} / \Sigma$ LNAA ratio at $t_{5}$. Consequently, elevated $\operatorname{Trp} / \Sigma$ LNAA ratios may have increased 5-HT synthesis during the placebo condition, thereby overestimating the behavioural effects of ATD. It might be suggested that this increase may be linked to some of the observed cognitive changes at $t_{5}$, notably those of the word learning test and fluency test, for which the effects disappear at $t_{9}$. This would imply that increased 5-HT activity actually improves memory. However, the fact that ATD was found to produce memory deficits compared to a placebo condition in which Trp/LNAA ratios were reduced as well (Riedel et al., 1999), strongly argues against this notion. Alternatively, it could be speculated that some unknown adaptive response to a reduction in 5-HT activity or even to reduced precursor availability occurred. Once again, this matter emphasizes the importance of a truly neutral control condition for ATD experiments. As yet, we assume that the primary mechanism responsible for the observed effects is lowered 5-HT function during the ATD condition. It has been proposed that the use of a Trp-free amino acid mixture may independently increase catecholamine turnover (Danjou et al., 1990). Lowered plasma Trp levels may stimulate the transport of the catecholamine precursor tyrosine into the brain, due to reduced competition for mutual transport sites. However, in our study, the ratio between tyrosine and the competing AA increased only slightly $\left(t_{5} \pm 15 \%, t_{9} \pm 14 \%\right)$ in both the ATD and placebo condition. It is therefore unlikely that elevated catecholaminergic activity was responsible for the observed differences between treatment conditions. Furthermore, even substantial tyrosine loading will not necessarily increase catecholamine synthesis (Young, 1996). The ratios for phenylalanine, which can be converted to tyrosine, also remained constant (at 10\%) between treatment conditions.

No substantial effects of ATD were seen on mood parameters. Although an effect was present for the vigour scale of the POMS, this existed only at $t_{9}$, whereas all observed cognitive changes already occurred at $t_{5}$. Apparently, the observed cognitive changes were not mediated by alterations in mood state. The absence of mood effects in this study is consistent with the notion that moodlowering effects of ATD predominantly occur in genetically vulnerable subgroups (Benkelfat et al., 1994; Klaassen et al., 1999). Indeed, in the present study, none of the subjects had a family history of depression.

Women have been found to be more susceptible to mood effects of ATD (Ellenbogen et al., 1996), but little is known about sex differences with regard to cognitive effects of ATD. Our data did not show sex differences in the effects of ATD on the cognitive functions or mood assessments. However, the present study was not specifically designed to investigate sex-related differences in the response to ATD, and failure to detect differences may be due to a type II error as a result of small group sizes ( 9 males versus 8 females). Since women show a more pronounced reduction in brain 5-HT synthesis after ATD (Nishizawa et al., 1998), it is conceivable that women are more sensitive to the cognitive effects of ATD. Future studies are needed to clarify this. We did not control for phase of the menstrual cycle during testing, and consequently some phase dependent variation in mood and perhaps cognitive performance may have occurred. Ideally, female volunteers should be tested in the follicular phase. However, with respect to memory performance, only modest effects of menstrual cycle are expected in healthy women (Sherwin, 1994). In addition, lack of sex differences on any of the outcome measures seem to indicate that phase of menstrual cycle did not affect results in a major way.

In conclusion, this study provides corroborating evidence that lowered 5-HT function specifically interferes with long-term memory consolidation in an early phase. Multiple assessments and the induction of ATD after acquisition of new information enabled us to further specify the nature of the memory deficits seen after ATD, showing that retrieval and short-term memory functions remain intact. Exploration of the effects of ATD on other cognitive functions particularly identified focussed attention, which showed 
a modality independent improvement by ATD, as a promising target for future research into the relationship between serotonin and cognition.

\section{Address for correspondence}

Jeroen A. J. Schmitt

Department of Psychiatry and Neuropsychology (Uns50)

Maastricht University

PO Box 616

6200 MD Maastricht

The Netherlands

Email: j.schmitt@np.Unimaas.nl

\section{References}

Altman H J, Normile H J (1988) What is the nature of the role of the serotonergic nervous system in learning and memory: prospects for development of an effective treatment strategy for senile dementia. Neurobiol Aging 9: 627-38

Amado-Boccara I, Gougoulis N, Poirier Littre M F, Galinowski A, Loo H (1995) Effects of antidepressants on cognitive functions: a review. Neurosci Biobehav Rev 19: 479-493

Bierer L M, Haroutunian V, Gabriel S, Knott P J, Carlin L S, Purohit D P, Perl D P, Schmeidler J, Kanof P, Davis K L (1995) Neurochemical correlates of dementia severity in Alzheimer's disease: relative importance of the cholinergic deficits. J Neurochem 64: 749-760

Benkelfat C, Ellenbogen M A, Dean P, Palmour R M, Young S N (1994) Mood-lowering effect of tryptophan depletion. Enhanced susceptibility in young men at genetic risk for major affective disorders. Arch Gen Psychiatry 51: 687-97

Bond A, Lader M (1974) The use of analogue scales in rating subjective feelings. Br J Med Psychol 80: 1-46

Burt D B, Niederehe G, Zemblar M J (1995) Depression and memory impairment: a meta-analysis of the association, its pattern, and specificity. Psychol Bull 117: 285-305

Coull J T, Sahakian B J, Middleton H C, Young A H, Park S B, McShane R H, Cowen P J, Robbins T W (1995) Differential effects of clonidine, haloperidol, diazepam and tryptophan depletion on focused attention and attentional search Psychopharmacology 121: 222-230

Cross A J (1990) Serotonin in Alzheimer-type dementia and other dementing illnesses. Ann NY Acad Sci 600: 405-417

Danjou P, Hamon M, Lacomblez L, Warot D, Kecskemeti S, Puech A J et al (1990) Psychomotor, subjective and neuroendocrine effect of acute tryptophan depletion in the healthy volunteer. Psychiatry Psychobiol 5: 31-38

Ellenbogen M A, Young S N, Dean P, Palmour R N, Benkelfat C (1996) Mood response to acute tryptophan depletion in healthy volunteers: sex differences and temporal stability. Neuropsychopharmacology 15: 465-474

Houx P J, Jolles J (1993) Age-related decline of psychomotor speed: effects of age, brain health, sex and education. Percept Motor Skills 76: 195-211

Klaassen T, Riedel W J, van Someren A, Deutz N E P, Honig A, van Praag H M (1999) Mood effects of 24-hour tryptophan depletion in healthy first-degree relatives of patients with affective disorders. Biol Psychiatry 46: 489-497

Lezak M D (1995) Neuropsychological assessment, 3rd edn. Oxford University Press, New York

Luteijn F, van der Ploeg F A E (1983) Handleiding Groninger Intelligentietest (GIT) [Manual Groningen Intelligence Test]. Swets and Zeitlinger, Lisse

McEntee W J, Crook T H (1991) Serotonin, memory, and the aging brain. Psychopharmacology (Berl) 103: 143-149
McNair D M, Lorr M, Droppleman L F (1971) Manual for the profile of mood states. Educational and Industrial Testing Service, San Diego, CA

Nishizawa S, Benkelfat C, Young S N, Leyton M, Mzengeza S, de Montigny C, Blier P, Diksic M (1997) Differences between males and females in rates of serotonin synthesis in human brain. Proc Natl Acad Sci USA 94: 5308-5313

Palmer A M, DeKosky S T (1993) Monoamine neurons in aging and Alzheimer's disease. J Neural Trans 91: 135-159

Park S B, Coull J T, McShane R H, Young A H, Sahakian B J, Robbins T W, Cowen P J (1994) Tryptophan depletion in normal volunteers produces selective impairments in learning and memory. Neuropharmacology 33: 575-588

Pollack I, Norman D A (1964) A non-parametric analysis of recognition experiments. Psychonom Sci 1: 125-126

Rey A (1964) L'examen psychologique dans les cas d'encephalopathie traumatique (Psychological assessment in cases of traumatic brain injury). Presses Universitaires de France, Paris

Reilly J G, McTavish S F B, Young A (1997) Rapid depletion of plasma tryptophan: a review of studies and experimental methodology. J Psychopharmacol 11: 381-392

Richter-Levin G, Segal M (1993) Age-related cognitive deficits in rats are associated with a combined loss of cholinergic and serotonergic functions. Ann NY Acad Sci 695: 254-257

Richter-Levin G, Segal M (1996) Serotonin, aging and cognitive functions of the hippocampus. Rev Neurosci 7: 103-113

Riedel W J, Klaassen T, Deutz N E P, Van Someren A, Van Praag H M (1999) Tryptophan depletion in normal volunteers produces selective impairment in memory consolidation. Psychopharmacology 141: 362-369

Robbins T W (1997) Arousal systems and attentional processes. Biol Psychol 45: 57-71

Rosse R B, Schwartz B L, Zlotolow S, Banay-Schwartz M, Trinidad A C, Peace T D, Deutsch S L (1992) Effect of a low-tryptophan diet as an adjuvant to conventional neuroleptic therapy in schizophrenia. Clin Neuropharmacol 15: 129-141

Rowley B, Van F, Mortimore C, Connell J (1997) Effects of acute tryptophan depletion on tests of frontal and temporal lobe function. J Psychopharmacol 11: A60

Shallice T (1982) Specific impairments of planning. Phil Trans R Soc Lond, Biol Sci 289: 199-209

Sherwin B B (1994) Estrogenic effects on memory in women. Ann NY Acad Sci 734:213-230

Sirvio J, Riekkinen P J, Jakala P, Riekkinen P J (1994) Experimental studies on the role of serotonin in cognition. Progr Neurobiol 43: 363-379

Smith A (1968) The Symbol Digit Modalities Test: a neuropsychological test for economic screening of learning and other cerebral disorders. Learn Disord 36: 83-91

Stroop J R (1935) Studies of interference in serial verbal reactions. J Exp Psychol 18: 643-662

Thompson P J (1991) Antidepressants and memory: a review. Hum Psychopharmacol 6: 79-90

Van Eijk H M, Rooyakkers D R, Deutz N E (1993) Rapid routine determination of amino acids in plasma by high-performance liquid chromatography with a $2-3$ microns Spherisorb ODS II column. J Chromatogr 620: 143-148

Welzin T E, Fernstrom J D, McConaha C, Kaye W H (1994) Acute tryptophan depletion in bulimia: effects on large neutral amino acids. Biol Psychiatry 35: 388-397

Wolfe B E, Metzger E D, Jimerson D C (1995) Comparison of the effects of amino acid mixture and placebo on plasma tryptophan to large neutral amino acid ratio. Life Sci 56 : $1395-400$

Young S N (1996) Behavioral effects of dietary neurotransmitter precursors: basic and clinical aspects. Neurosci Biobehav Rev 20: $313-323$

Young S N, Smith S E, Pihl R O, Ervin F R (1985) Tryptophan depletion causes a rapid lowering of mood in normal males. Psychopharmacology (Berl) 87: 173-177 